\title{
The use of innovative pedagogical technologies in music education
}

\author{
Nataliya Alekseenko ${ }^{1 *}$, and Daniela Rakich ${ }^{2}$ \\ ${ }^{1}$ V.I. Vernadsky Crimean Federal University, Simferopol, Russia \\ ${ }^{2}$ Music Academy of East Sarajevo, Bosnia and Herzegovina
}

\begin{abstract}
The article considers the use of the main innovative pedagogical technologies in the process of students' professional musical training which will help to increase the efficiency of training specialists in the field of musical art. Presented is the use of all the pedagogical technologies and their functions in the process of musical training in order to improve the quality of future professional musicians' training.
\end{abstract}

\section{Introduction}

The modern system of music education is characterized by essential innovative changes featuring innovative approaches to the problems of education. The need to update the content and quality of future musicians' professional training has become urgent. Musicians' professional training under modern conditions presupposes the obligatory introduction of innovative pedagogical technologies in the educational process to make it more efficient. It is essential to enrich pedagogical knowledge with innovative technologies in music training which should be selected from a wide range of the pedagogical technologies applied in the system of higher education.

The problem set in the article touches upon a wide range of research interests presented in the studies by both domestic and foreign authors: V. V. Vasilyevich. P. Bespalko, M.V. Clarin, Z.A. Litova, B.T. Likhachev, A.S. Petelin, G.K. Selevko, V.A. Slastenin, F.F. Yanushkevich, I.B. Gorbunova, D. Lebrer, R. Hammer, D. Kellner, E. Frolova, T. Ryabova, O. Rogach, et al. They consider the problems of pedagogical technologies and their use in higher education institutions.

The purpose of the article is to identify the innovative pedagogical technologies which may prove effective in music education.

\section{Research questions}

Unlike the traditional format of the pedagogical system of musicians' professional training, which emphasizes methodological recommendations and instructions, the pedagogical technology offers a project of the educational process determining the structure and content of students' educational activity.

\footnotetext{
*Corresponding author: alekseenkonata@mail.ru
} 
Researchers in music pedagogy consider that the dominant teaching practices of the past should be rethought. It is essential to search for new alternatives probably resulting in graduates' acquiring the skills and tools necessary to adapt quickly to the changing environment [1].

Thanks to the research conducted by V.P. Bespalko [2], I.I. Markhel [3], K. Selevko [4], et al., a sufficient stock of factual material has been accumulated allowing for a deeper understanding of real and predicted results of students' learning activities when replacing the learning objectives. The analysis of the available scientific publications has allowed for the study of various approaches to the innovative technologies' classification. Pedagogical practice requires the designing of a relatively simple and at the same time universal toolkit for music students' personal and professional development. Such a toolkit requires the disclosure of the development's structure and its dynamics in innovative learning technologies and modeling the educational environment.

In the modern training process it is necessary to use both traditional and innovative methods of training, the latter being not less effective, and in some cases it is impossible to do without them. It is necessary that they are in constant interconnection, thus complementing each other. These two concepts should exist on the same level.

The innovative pedagogical process presupposes the new elements' introduction in the purposes, content, forms and methods of education and upbringing. Moreover, it calls for the joint activity of the educational process's participants.

Innovative educational activity is a complex process requiring skilled and structural management. The introduction of innovative pedagogical technologies changes the educational process considerably. It helps to solve the problems of the developmental and person-oriented training, differentiation, humanization and the formation of individual educational perspectives.

Innovative learning is the constant striving for values' reappraisal, preserving undeniable ones and rejecting those which have already become outdated. Innovations in educational activities are connected with an active process of creation and distribution of new methods and means for solving didactic tasks of professional training in a harmonious combination of classical traditional methods and the results of creative search, application of non-standard and progressive technologies, original didactic ideas and forms of educational process provision.

Innovative technologies used in the system of higher education consist in teachers' modeling the content, forms and methods of the educational process, provided that they are novel and meet the goal. In practice, modern higher education institutions use such technologies as differentiated, problem and contextual learning, game learning technologies, information technologies, person-oriented learning, etc.

One of the types of modern innovative teaching technologies' application in the process of future musicians' professional training is the teaching medium. To use it successfully and purposefully, teachers of higher education institutions should know their didactic capabilities and functioning principles.

Modern information technologies' efficiency in the process of future musicians' professional skills development is provided by various forms of information presentation, the high degree of visibility and the design of both team and individual tasks.

Consequently, educational innovations are characterized by the intentional process of partial changes leading to the modification of the purpose, content, methods and forms of musicians' training, the ways and style of their activities, the educational process's adaptation to the modern requirements and demands of the labor market. Besides, the introduction and approval of the new elements in educational practice is conditioned by positive transformations and, consequently, should become a means for solving the essential problems of a certain educational institution and stand the experimental test for the 
final application of innovations. First of all, it should consist in the modern modeling and introduction of non-standard individualization means of education; classroom, group and further education; optional deepening of knowledge (on students' demand); problemoriented education; research elements in new material's mastering; development of a new monitoring system of knowledge assessment; application of computer and multimedia technologies; new-generation educational and methodological materials [5].

It is not sufficient to realize the importance of changes in musicians' training. There is a need to develop a strategy for such changes, from logistics to training the teaching staff who would be able to implement them. After all, the success of any activity in higher education institutions is largely determined by the degree of teachers' readiness to implement it [6]. At the same time, teachers should not only have the necessary knowledge, but also psychologically reorganize themselves, be internally aware of the need for such work and actively self-determine themselves in relation to it. In the final analysis, only teachers have a clear understanding of the goals of teaching, know the content of educational materials, the teaching methods and means, make decisions how to design the learning process, determine the course of teaching activities and prepare the conditions allowing for their visions becoming real.

The introduction of innovative technologies in the process of future musicians' professional training helps them to master the educational material at an individual pace, independently, using convenient methods of information perception, causes positive emotions and forms positive motivation for learning. The educational profession-oriented information environment is created in order to develop musicians' performing skills and intensify musicians' professional training in higher educational institutions by means of the introduction of computer presentations, electronic dictionaries, textbooks and manuals, test programs, master classes, video clips containing outstanding modern musicians' performances, video lessons, electronic visual aids, etc.

The content of information-development technologies is aimed at developing musicians' performing skills and mastering the necessary system of knowledge and a large stock of information, including a variety of classroom activities and students' individual work. The increase in the efficiency of musicians' classroom activities is based on the use of multimedia technologies taking into account musician' individual performing styles, the specificity of music education and the level of students' musical skills.

The available software tools will allow students to carry out reflexive activity and indicate the level of their professional progress in the development of performing skills in the real-time mode. It helps to sort out the musical content according to complexity levels and create a positive emotional background for musicians' work with the information means of education.

Besides, an important component of the pedagogical skills is the future teachers' information culture, i.e. the ability to read books productively, find necessary information, comprehend and pass it on to others.

The use of information technologies in this context will contribute not only to the increase in musicians' motivation and their critical thinking, but also to the implementation of active forms of constructive communicative interaction [7].

The development of information culture is facilitated by students' individual and research work requiring individual approaches and affecting their individual styles in professional activity. The effective methods of such work include individual educational and research tasks, such as a scientific report, which is a publicly-spoken message and a detailed presentation of a particular scientific problem.

One of the important components of the educational process in higher education institutions is students' research activity including scientific reports, articles, theses, abstracts, term papers, graduation theses, etc. The modern network means of 
communication and the World Wide Web promote the introduction of problem-research computer methods of education into the process of musicians' professional training.

Students' research work is an integral part of information technologies' application contributing to the development of musicians' information competence and professional skills. In the process of scientific activity, musicians acquire knowledge which is the informative basis of heuristic activity, learn the ways and actions determining the operational basis of search and cognitive activity and become experienced both in information activities in the field of software and the «man-computer» relationship.

Among the most important innovative technologies in musicians' professional training one can mention the project-oriented training technology, which helps students to solve professional tasks individually, present and defend the results of their creative and scientific work [8].

The project-oriented training technology includes many specific forms, techniques and methods aimed at developing students' creative, research and analytical skills. In this case, not only the idea is developed, but also the conditions for its implementation. It can be perceived, tested and used in real practical activities. To achieve such a result, students need to recognize and solve problems on their own. To do this, they should make use of comprehensive knowledge, the ability to predict the results and the permissible consequences of different options for the problems' solution and establish the cause-andeffect relationship. This technology is based on the idea that students' educational-cognitive and creative activity should be result-oriented, which is obtained by solving one or another practically or theoretically significant problem.

In educational practice, the diversification of pedagogical technologies makes it possible to combine them actively and efficiently by means of updating traditional education to make it more effective and purposeful. This approach emphasizes musicians' personal development, their ability to acquire new experience in creative and critical thinking, role and simulation modeling of the search for solutions to educational problems, etc.

T.D. Smelkova singles out integration as one of the main innovative pedagogical technologies in musicians' professional training. According to the researcher, the integration approach is the most important mechanism in forming musicians' performing culture. At the same time, integration in the educational process presupposes the closest substantial interaction of disciplines. Such a connection should be established not only with individual creative classes (playing the specified musical instruments, conducting, ensemble and orchestra), but also with a range of musical-historical and psychologicalpedagogical disciplines.

Researchers from developed countries pay special attention to the inclusion of new media technologies of education in the traditional educational process [9]. The main attention in their research is paid to the study of opportunities and limitations in the use of interactive technologies in order to form students' media competence. In contrast to traditional teaching methods encouraging «learning for assessment», interactive technologies activate students' conscious need for «learning for self-development». The authors highlight the following advantages of interactive methods: developing skills for media landscape segmentation and the critical approach to the choice of media texts for further analysis; the use of the multidimensional approach to the choice of information channels, the volume of information and units of media text analysis. The information abundance in the Internet and the prevalence of traditional tasks shapes consumers of media information. In the absence of real practice of media competence shaping, the use of interactive learning methods can be limited to the text selection by students [10].

The systematic use of multimedia educational technologies allows raising efficiency of experts' professional training according to the modern requirements of the society [11]. 
At the same time, designing the creative information environment for musicians' professional potential realization is of great importance in students' professional training. The introduction of information and communication technologies in the process of training future specialists in musical art is one of the weighty factors of their professional and personal experience's enrichment. The purpose of informatization of the music education's system is to increase the training efficiency through the expansion of information and the improvement of its application methods. Reorientation of modern music education from discreteness to continuity requires the development and experimental testing of new forms of didactic interaction with music teachers, aimed at forming professional musicians' positive motivation.

The informatization of music education is connected with the functioning of high-tech educational creative environment, the designing of new approaches and fundamentally new methods of education aimed at transforming musicians' professional activity. Nowadays, innovative music pedagogy is associated with musical computer technologies - a modern and effective means of improving the quality of music education at all levels of the educational process. Musical computer technologies are an indispensable tool allowing different categories of students to master the highly artistic music culture. The necessity to change musicians' activity and the content of music education in the context of digital educational resources implies the active development of the Russian school of electronic musical instruments' performing skills as one of the forms of computer music technologies [13].

It is necessary to apply integration technologies not only in using inter-subject links, but also in all directions of the educational process.

The formation of the integral performing culture is also connected with the integrative approach to the use of various creative forms of education in the educational process: open lessons, master classes, creative workshops, training concerts, competitions, pedagogical workshops, conferences and listening to audio and video recordings with subsequent analysis [14].

In her research, V. P. Petrova proposes to use the structural and functional model of improving musicians' professional training on the basis of the integrated approach. It includes the methodological system of technological training methods: «sketch mastering of musical works»; «joint teacher-student performing»; «conversation on music»; «virtual performance»; «polyphonic mastering of musical texts». These can serve as the basis for musicians' successful intermediate vocational education.

At present, the improvement process of musicians' professional training proves really effective under the conditions of the integrated approach connected not only with the comprehension of the basic principles of instrument performance, but also with the mastering of other kinds of art-oriented creative activity [15].

It should be noted that it is the integrative immersion in the music culture that contributes to musicians' professional becoming.

Another innovative pedagogical technology, which is essential in the process of musicians' professional training, is the technology of cooperation (partner technology). It provides for the combination of subject-centered and personality-centered training. Teachers strive for both the acquisition of the subject matter and the development of a musician's personality. They intend to encourage students to acquire maximum specific knowledge, skills and understanding of general rules combined with the development of their own «selves», personal judgment and other qualities necessary for musicians.

The study program on technology cooperation is diverse and its implementation is quite complicated because it is necessary to combine the complex scientific approach with the spiritual side of one's personality, so that every student could feel more trained, personally developed and satisfied after every lesson. This technology is difficult to use in practice. It 
has several purposes: to teach, to develop and to educate. All these purposes are interconnected, which implies one's personality development and education, as well as the creation of conditions for personal self-fulfillment. All this requires a high level of professionalism on the part of teachers.

The main content of the pedagogy of cooperation does not consist in the implementation of the educational process's goals. It rather includes the methods, techniques and forms used in its implementation. Within its framework, a system of well-coordinated ways of activity has been developed: the use of schematic visibility, commenting on students' performance, restructuring the teacher-student relationship, providing individual assistance to students, additional demonstration of correct performance samples, the use of guiding, supportive and probing questions in order to direct students' thoughts, etc.

One of the basic innovative technologies necessary for musicians' effective professional training is the theatrical technology. It promotes comprehension of occurring events and actions in the course of creative cognition and freedom of performing activity under the conditions of concert halls and theatrical stages. The application of the theatrical technology in the development of musicians' professional qualities involves the implementation of a set of means aimed at performers' participation in the stage action and immersion in the artistic image of musical compositions [15].

The importance of introducing theatrical technologies at the stage of musicians' evolvement consists in the formation of their technical-operational, artistic-performing and personal-activity qualities.

The use of the theatrical technology has a significant pedagogical potential for the development of musicians' professional qualities. It activates and integrates the techniques of stage embodiment of a variety of musical repertoire, point effect and the immersion in musical compositions' artistic image, which greatly expands the pedagogical possibilities of training and creates the best possible conditions for students' professional and personal development [15].

The use of the theatrical technology develops the sense of pitch and trains the ability to distinguish the emotional expressiveness of musical compositions. At the same time, it forms the ability to notice the mood of the surrounding people and their state of mind, develops the sense of compassion and sensitivity to others, lay down certain ethical and aesthetic norms, and nurture the desire for beauty.

As the creative component of education grows essentially, the roles of all the participants of the educational process are activated, students' creative search independence strengthens and the concepts of individual-oriented and problem training acquire particular urgency.

The individual-oriented technology is focused on students. The educational materials complement students, so to say. The aim is to develop one's personality, not just to master the subject. The indicator of learning is not the quantity and quality of learning, but the progress of one's personality: the development, emancipation of one's own «self», selfunderstanding, self-determination, freedom and independence of opinions, etc. Students are the pivot of the learning process, and if they do not want to learn, the process is compressed, deformed or stopped altogether. The quantity and quality of specific knowledge and skills are not of great importance. The main criterion is the satisfaction of personal needs, creating conditions for musicians' realization of personal potential in their profession and career.

The personal approach becomes inherent in modern higher education. Its manifestation in the pedagogy of cooperation has turned into a certain style of relations in democratically spirited schools: students are treated positively, their aspirations, thoughts and even mistakes are respected because free people protected by democratic rights and freedoms, cannot be forced to tolerate teachers' professional incompetence, let alone their rudeness or 
wrongly chosen styles of communication. A person designing his or her own educational trajectory stops being an impersonal object of the pedagogical process. Rather, this process is carried out to satisfy their needs.

The basis of this technology is the idea of person-oriented learning. This being so, numerous directions, systems, models and modifications of the so-called light, gentle, personalized, customized, differentiated, etc. learning are being developed in the modern world. Higher education institutions and teachers provide students with the services they need to the extent they need. Students have the opportunity to choose their own courses of study, set their level of learning (elementary, intermediate, advanced or fluent), study according to their needs, strengths and capabilities, move at their own pace, get grades or not, and invite various teachers to assist them.

The technology of individualized instruction has incorporated the following advances in democratic way of life and the new developments in pedagogical thought:

- respect for people's democratic freedoms, primarily the right to the free choice of education;

- long experience of education's functioning under the market economy conditions, which led to its complete reorientation to meet people's needs;

- dissemination of the ideas of education's humanization, according to which a person is recognized as the supreme value of education;

- provision of a real opportunity to fully meet the needs of each person in accordance with his or her intentions, goals and life strategy.

In our version, the emphasis in musicians' personalized training is placed as follows:

- the goal of individualized learning is to emphasize the development of values and meaning;

- discarding the concept of personality formation and approving the concept of its development's promotion;

- students are subjects of life, not of learning;

- strengthening the dialogical character of teachers' communication with students;

- spiritual communication with students;

- studying students' personal qualities and the dynamics of their development;

- support of positive trends in students' personal development;

- assistance in overcoming negative tendencies.

Despite the numerous approaches in pedagogical and psychological science, as well as work patterns applied in various higher educational institutions, nowadays teachers, educational institutions and even regions should choose their own reference points of musicians' professional training based on innovative technologies' introduction.

The modern didactic research in contextual learning technologies is characterized by an orientation to the close connection of the learning process with students' immediate needs, interests and experience. Each student has his or her unique personal experience, which should be taken into account and relied upon in musicians' professional training.

When choosing a pedagogical technology, it is important to bear in mind that the following three conditions are important for its successful implementation:

- studying the technology and mastering it thoroughly;

- determining which category of students it is intended for, and whether a particular student needs it;

- providing oneself with the constant access to the theoretical, methodological, and didactic materials on the technology.

It should be noted that the introduction of innovative technologies in the process of musicians' professional training shows an increase in performing skills and professional competence of future musicians who participate in the innovative processes. These processes improve the quality indicators of students' educational achievements. On the 
other hand, the regional system of education as a whole is being modernized. Higher educational institutions conduct research, thus developing, mastering and implementing innovative pedagogical technologies. The educational institutions' development is provided with scientific and methodological support. Future specialists are encouraged to develop the modern style of thinking with its characteristic features: creativity, consistency, flexibility, dynamism, perspective, objectivity, conceptuality, etc.

\section{Conclusions}

Thus, having defined the innovative technologies of future musicians' professional training, we can come to the conclusion that their implementation, along with traditional training, will significantly improve musicians' professional level in higher education institutions. The problems of innovative pedagogical technologies' differentiation require further research taking into account a variety of musicians' training programs and the specification of forms and methods of each pedagogical technology.

\section{References}

1. D. Lebler, Student-as-Master? Reflections on a Learning Innovation in Popular Music Pedagogy, International Journal of Music Education, 25, 205-221 (2007)

2. V.P. Bespal'ko, Personified Education, Pedagogika, 6, 12-17 (1998)

3. I.I. Marhel', On the Classification of Computer Technologies in Education, New Information Technologies in Ukraine's Educational Institutions, 275 (1999)

4. G.K. Selevko, Modern Technologies in Education, Narodnoe obrazovanie Publ, 256 (1998)

5. V.N. Paderin, The Use of Multimedia Technologies in University Students' Training, https://cyberleninka.ru/article/n/ispolzovanie-multimediynyh-tehnologiy-v-obucheniistudentov-vuzov

6. N.O. Petrova, Effective Methods of Students' Professional Training, Yuzhnorossijskij Muzykal'nyj Al'manah, 39-43 (2017)

7. A.S. Parfyonova, Information Technologies in University Students' Training, https://cyberleninka.ru/article/n/informatsionnye-tehnologii-v-obuchenii-studentovvuza

8. V.A. Kapranova, Technology of Project-oriented Education in Higher Education Institutions: Theory Translated into Practice, https://core.ac.uk/reader/74328834

9. R. Hammer, D. Kellner, Multimedia Pedagogy for the New Millenium, Journal of Adolescent \& Adult Literacy, 42, 522-526 (1999)

10. E. Frolova, T. Ryabova, O. Rogach, Interactive Technologies of Forming the Students' Media Competence: Opportunities and Limitations of Their Use in Contemporary Educational Practice, Mediaobrazovanie, 4, 22-28 (2018)

11. N.V. Bakhmat, T.Y. Dudka, V.V. Liubarets, Multimedia Education Technologies Usage as the Condition for Quality Training of the Managers of Socio-cultural Activity, Informacionnye Tekhnologii i Sredstva Obucheniya, 64, 98-109 (2018)

12. N.M. Popovich, Information and Creative Educational Environment as a Prerequisite for Professional Creative Self-realization of Music Specialists, Informacionnye Tekhnologii i Sredstva Obucheniya, 69, 92-99 (2019) 
13. I.B. Gorbunova, The Concept of Music Computer Pedagogical Education in Russia, International Journal of Advanced Science and Technology, 29, 600-615 (2020)

14. V.G. Gul'chevskaya, Integrative Technological Model of Schoolchildren's Pedagogical Support in the Learning Process (Practice-oriented Monograph, 150, 2017)

15. N.O. Petrova, Effective Methods of Students' Professional Training, Yuzhnorossijskij Muzykal'nyj Al'manah, 39-43 (2017)

16. G.I. Ibragimov, Problem-based Learning in the System of Higher Education: State-ofthe-Art and Development Trends, https://cyberleninka.ru/article/n/problemnoeobuchenie-v-sisteme-vysshego-obrazovaniya-sostoyanie-i-tendentsii-razvitiya 